\title{
The Role of Flood Surge Plays in Shaping Tidal Flat
}

\author{
X. Q. Du* \\ School of Geographic and Oceanographic Sciences, Nanjing University, Nanjing 210093, China \\ Email: xiaoqdu@163.com
}

\begin{abstract}
In the tidal flat environment, flood surge has been studied since 1980's and was firstly defined in 1989. More important progress had been made in 1990's. It was claimed that tidal flat was shaped by flood surge and characterized by flow acceleration process. It was also declared that the temporal and spatial change of the impact depends on the rates of water level changes. However, it lacks of credibility in the effect of flood surge working on tidal flat by acceleration. And the process is not yet understood. Therefore, more attention should be paid to flood surge. This study focused on the role of flood surge in constructing tidal flat and how it does.

During July 3-10, 2003, MIDAS-400 was deployed on the intertidal flat at Wanggang, north Jiangsu to measure tidal current speeds and seawater densities at six layers above seabed. In this paper, the data measured at the lowest layer were used to represent the characteristic of very shallow water. Theoretical analysis was performed to deduce the duration of flood surge and compare the speeds at a site at different time. In order to eliminate the influence of turbulence, the data were averaged in 5 minutes. The flow speeds at the beginning of the floods with smaller water depthes were larger than those of other time during floods. The seawater densities were highest at the beginning of floods and keeping high quantity for much longer time. Correlation coefficient between seawater densities and largest rates of water level changes was 0.90 which was much larger than critical coefficient 0.71 at the confidence level of $95 \%$ for six pairs of data. Analysis indicated that seawater densities were directly proportional to the rates of water level changes while there was little correlation between seawater densities and flow acceleration. It may be concluded that flood surge is characterized by the largest rate of water depth change.

The way flood surge affects shaping tidal flat may be supposed as: the weighty mixture of water and sediment tamps on flat surface directly, water on the flat is accelerated and the resting sediment is started by the impact of the flood surge simultaneously. The suspended particles are taken by the succeeding flood water towards shore line so that seawater density keeps high quality for much longer time and the tidal flat is then shaped. The effect can be called hammer effect here which is also influenced by climate (wind and rain). The absence of suddenly change of flow spced and water depth is caused by the limit of instrument and the rainy/windy climate during the measurement might lead to errors. However, the hypothesis was coincident with the those in field data.
\end{abstract}

\section{REFERENCES}

1. Wang Y P, Zhang R S, Gao S. Velocity variations in salt marsh creeks, Jiangsu, China. Journal of Coastal Research, 1999;15(2):471-477

2. Xu Y, Wang B C. The mechanism and significance of flood surge along muddy tidal flat. Oceanologia et Limnologia Sinica, 1998;29(2):158-155 